\title{
Thermoplastic Blends Based on Poly(Butylene Succinate-co-Adipate) and Different Collagen Hydrolysates from Tanning Industry: I-Processing and Thermo-mechanical Properties
}

\author{
Maurizia Seggiani ${ }^{1}$ (1) $\cdot$ Roberto Altieri $^{2} \cdot$ Patrizia Cinelli $^{1} \cdot$ Alessandro Esposito $^{2} \cdot$ Andrea Lazzeri $^{1}$
}

Published online: 19 September 2020

(c) The Author(s) 2020

\begin{abstract}
In this study, blends of a biodegradable thermoplastic polyester, poly (butylene succinate-co-adipate) (PBSA) with two different raw hydrolyzed collagens (HCs), derived from the tannery industry, were investigated in terms of processability, rheological, thermal and mechanical properties. HCs, obtained by alkaline (HCa) and enzymatic (HCe) hydrolysis of the solid wastes generated during the shaving of the tanned leather, were used in PBSA/HC blends, up to $20 \mathrm{wt} \%$ of $\mathrm{HC}$, produced by melting extrusion and processed by injection molding. All the blends up to $20 \mathrm{wt} \% \mathrm{HCs}$ resulted suitable for the injection molding obtaining flexible molded specimens with good tensile properties. The different secondary structure of the two HCs influenced the rheology, morphology and mechanical properties of the produced blends. In particular, $\mathrm{HCa}$, due its higher content of oligopeptides and free amino-acids, showed a good compatibility with the polymeric matrix acting as a plasticizer with consequent reduction of melt viscosity with increasing its loading. The molded dog-bones specimens containing 20 $\mathrm{wt} \% \mathrm{HCa}$ showed a value of elongation at break of $810 \%$. While, HCe, due its higher presence of b-sheet structures, behaved as organic filler, showing a poor interfacial interaction with PBSA with consequent decrease of the tensile properties with increasing its loading. The good processability and satisfactory mechanical properties obtained encourage the use of both investigated collagen hydrolysates in the production of thermoplastic blends and relative molded products for applications in agriculture and plant nurseries, such as pots or small containers with fertilizing properties, due the presence of HCs.
\end{abstract}

Keywords Poly (butylene succinate-co-adipate) · Hydrolyzed collagen · Tannery industry · Thermoplastic blends . Injection molding

\section{Introduction}

Among the commercially available biodegradable plastics, poly (butylene succinate-co-adipate) (PBSA) is a promising thermoplastic aliphatic polyester with many interesting properties: excellent processability in extrusion, thermoforming, film blowing and injection molding, biodegradability

Maurizia Seggiani

maurizia.seggiani@unipi.it

$\triangle$ Roberto Altieri

roberto.altieri@cnr.it

1 Department of Civil and Industrial Engineering, University of Pisa, Largo Lucio Lazzarino n. 2, 56122 Pisa, Italy

2 Institute for Agricultural and Forest Systems in the Mediterranean, Consiglio Nazionale Delle Ricerche, (ISAFoM-CNR), Via della Madonna Alta 128, 06128 Perugia, Italy in different environments (industrial/home composting and soil), and good mechanical performance similar to that of polyolefins [1-6]. PBSA is a random co-polyester synthetized by the reaction of 1,4-butanediol with aliphatic dicarboxylic acids such as succinic and adipic acids, and it is commercially available in different grades (molecular weights from 10,000 to $100,000 \mathrm{~g} / \mathrm{mol}$ ) for various applications [1-3]. Some manufactures, such as Mitsubishi Chemical, produce partially biobased poly (butylene succinate), PBS, and PBSA having $54 \mathrm{wt} \%$ biobased content derived from biobased succinic acid [7], although synthetic PBS and PBSA are still the most common products on the market [8]. Compared to PBS, PBSA exhibits a higher rate of biodegradation in industrial composting and recent studies have reported that PBSA, in forms of films and molded items, results biodegradable within few months in soil, sea water and water with activated sludge [3, 4, 6-9]. PBSA shows higher impact strength and elongation, lower tensile 
strength and melting point respect to PBS, due to its lower crystallinity and higher flexibility of its polymer chains [9]. For these reasons, PBSA results more attractive respect to PBS for those applications where the biodegradability in soil can become the key prerequisite such as molded plant pots and agricultural mulching films. In fact, pure PBSA films are proposed as bag liners, mulch film and agricultural films [10]. Despite these attractive properties, the use of PBSA in short-term applications is still very slowed by its relatively high cost (5-6€/kg, info from MCCP Germany $\mathrm{GmbH}$ ) compared to that of the petroleum-derived, nonbiodegradable, plastics and also of other bioplastics, such as poly-lactic acid (PLA). So, in order for PBSA to be more attractive for commodities, the addition of low-cost biodegradable and renewable components in blend can represent a strategy to produce biodegradable PBSA-based blends with improved cost competitiveness. For this reason, PBSA has been successfully blended with corn starch $[1,11,12]$ to obtain biodegradable composites with good processability and mechanical performances.

For the same purpose, also waste protein hydrolysates such as hydrolyzed collagens (HC) from tanning industry could be used in blend with PBSA given the well-known good adhesive properties of proteins and their good melt processability. Different authors have studied blends containing $\mathrm{HC}$ and synthetic polymers such as polycaprolactone (PCL) [13, 14], polyvinyl alcohol (PVA) [15, 16], low-density polyethylene (LDPE) [17, 18] and polyvinylchloride (PVC) [19] showing the positive effect of the HC on the blend processability by conventional melting-based processes.

The addition of HCs to PBSA can lower the cost of the final item as well as improve the biodegradability of the polymer supporting the microbial growth upon environmental exposure and give to the final product fertilizing properties given the presence of protein nitrogen. To our knowledge, only our work has been reported in scientific literature concerns preliminary encouraging results of processing the PBSA with raw hydrolyzed collagen derived by alkaline hydrolysis of leather shavings by blow-film molding [20].

Shavings along with fleshings represent the most important solid by-products of the tannery industry and are mainly constituted of raw collagen. The shaving process is carried out after tanning to reduce and/or even out the thickness throughout the tanned or crusted leather. The leathers are put through a machine with a rapidly revolving cylinder cutting fine, thin fragments from the flesh side. The small pieces of leather which are shaved off are called shavings. In Italy, such wastes derived from leather districts, such as Santa Croce sull'Arno (Pisa, Italy) and Arzignano (Vicenza, Italy) are collected and processed in centralized plants where, through alkaline or enzymatic hydrolysis, degreasing, concentration, centrifugation and, eventually, spray-drying, collagen hydrolysates in solution or powder are produced. Actually, these hydrolysates are used as organic fertilizers in agriculture due to their relatively high nitrogen content (about 13-15 wt \%) and moderate salt content. The collagen hydrolysates from the leather industry are available at low cost (1.20 €/kg powder, info by Consorzio SGS, Santa Croce sull'Arno, Pisa, Italy) and their use, unlike corn starch, is not in competition with food industries.

Thus, the present work focuses on the addition to PBSA of two different raw hydrolyzed collagens (HCs), obtained from leather shavings by different hydrolysis processes (alkaline and enzymatic hydrolysis), with the aim of developing thermoplastic biodegradable blends with improved cost competitiveness, maintaining good processability and mechanical performance.

In particular, PBSA/HC blends with 5, 10, 15 and $20 \mathrm{wt} \%$ of $\mathrm{HC}$ were produced by melt extrusion and the resultant pellets were processed by injection molding. The blends were characterized by Scanning Electron Microscopy (SEM) coupled with an energy dispersive X-ray spectrometry (EDS), by Fourier Transform Infrared (FTIR) analysis in order to evaluate the dispersibility of HCs into the polymer matrix and to evaluate the intermolecular interactions between PBSA and HCs, respectively. Furthermore, the rheological behavior of the blends was investigated to evaluate the effect of HCs on the melt viscosity and the molded dog-bone specimens were characterized by tensile tests.

\section{Experimental}

\section{Materials}

Pellets of PBSA (trade name BioPBSTM FD92PM) were purchased from MCCP Germany GmbH (Mitsubishi Chemical Co., Tokyo, Japan). FD92PM is produced by copolymerization of bio-based succinic acid and adipic acid with 1,4-butanediol $[3,20]$, having a melting temperature of $84{ }^{\circ} \mathrm{C}$, density of $1.24 \mathrm{~g} / \mathrm{cm}^{3}$, melt flow rate (MFR) of $4 \mathrm{~g} / 10 \mathrm{~min}\left(190^{\circ} \mathrm{C} / 2.16 \mathrm{~kg}\right)$, suitable for blown film applications (i.e., bag liners, mulch film, agricultural film). FD92PM is a food contact grade in accordance with EU10/2011 and certified home compostable and biodegradable in soil by Vinçotte. Two types of hydrolyzed collagen from tannery industry were used: an hydrolyzed collagen derived from alkaline hydrolysis of shavings, labeled as $\mathrm{HCa}$, supplied by Consorzio SGS SpA (Santa Croce sull'Arno, Pisa, Italy) in form of dark yellow granules, and an hydrolyzed collagen derived from enzymatic hydrolysis of shavings, HCe, supplied by ILSA S.p.A. (Verona, Italy) in white powder form. Figure 1 shows the two HCs used in this work.

The composition of the two HCs, provided by suppliers, is reported in Table 1. As shown, HCa shows higher content 


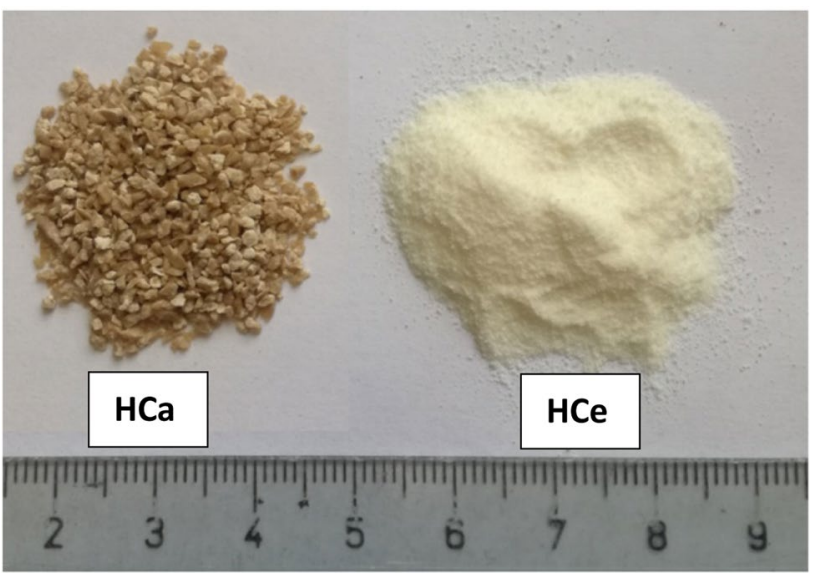

Fig. 1 Hydrolyzed collagens ( $\mathrm{HCa}$ and $\mathrm{HCe}$ ) used in this work

Table 1 Properties of the $\mathrm{HCs}$ used in preparation of PBSA/HC blends

\begin{tabular}{lll}
\hline Property & $\mathrm{HCa}$ & $\mathrm{HCe}$ \\
\hline Dry matter $\left(\right.$ at $\left.103{ }^{\circ} \mathrm{C}, \mathrm{wt} \%\right)$ & 97.0 & 99.9 \\
Ash $\left(\right.$ at $\left.550{ }^{\circ} \mathrm{C}, \mathrm{wt} \% \mathrm{db}\right)$ & 7.3 & $<1$ \\
Bulk density $(\mathrm{kg} / \mathrm{L})$ & 0.50 & 0.55 \\
Total nitrogen $(\mathrm{wt} \% \mathrm{db})$ & 14.1 & 15.9 \\
Organic nitrogen $(\mathrm{wt} \% \mathrm{db})$ & 13.2 & 15.9 \\
Organic carbon $(\mathrm{wt} \% \mathrm{db})$ & 43.7 & 49.5 \\
Organic matter $(\mathrm{wt} \% \mathrm{db})$ & 87.4 & 99.0 \\
NaCl content $(\mathrm{wt} \% \mathrm{db})$ & 7.8 & $<1$ \\
Total amino acids $(\mathrm{wt} \% \mathrm{db})$ & 88.9 & 99.0 \\
Free amino acids $(\mathrm{wt} \% \mathrm{db})$ & 39.7 & 0.6 \\
pH in aqueous solution & 5.3 & 6.1 \\
Water solubility $(1: 4, \mathrm{w} / \mathrm{v})$ & Total & Almost total \\
\hline
\end{tabular}

$d b$ dry basis

(about $40 \mathrm{wt} \%$ on dry basis) of free aminoacids compared to $\mathrm{HCe}$ (below $1 \mathrm{wt} \%$ ). Both HCs, being highly hydrophilic, in particular $\mathrm{HCa}$, were dried under vacuum at $50{ }^{\circ} \mathrm{C}$ for $24 \mathrm{~h}$ before use.

\section{Blend Production and Processing}

PBSA/HC blends were prepared by melting extrusion in a semi-industrial twin screw extruder, a Comac EBC 25 HT (Comac, Milan, Italy), feeding dried pellets of the pure
PBSA in the main feeder hopper and the granules/powders of $\mathrm{HCa}$ and $\mathrm{HCe}$ by a side-feeder in adequate weight ratios to obtain blends with 5, 10, 15 and $20 \mathrm{wt} \% \mathrm{HC}$, respect to the total weight, labeled as PHa5, PHe5, PHa10, PHe10, PHa15, PHe15, PHa20, PHe20, respectively. The temperature profiles set in the extruder (from the first zone after the main feeder to the head zone) for the PBSA/HC blends are reported in Table 2 with the temperature and pressure of the melt measured at the nozzle exit of $125^{\circ} \mathrm{C}$ and $12 \mathrm{~atm}$, respectively, for the $\mathrm{PHa}$ blends and $133{ }^{\circ} \mathrm{C}$ and $25 \mathrm{~atm}$ for the PHe blends. The screw speed was $250 \mathrm{rpm}$ for both blends. The extruded filaments were cooled in a water bath at room temperature and reduced in pellets by a pelletizing unit equipped with rotating blades. The pellets, after drying at $60{ }^{\circ} \mathrm{C}$ for $12 \mathrm{~h}$ in a Piovan dryer (DP 604-615, Piovan, Venezia, Italy), were processed in an injection press (model Mega Tech H10/18-1, Tecnica Duebi srl, Ancona, Italy) to produce specimens (Haake III type dog-bone tensile bars: width $10 \mathrm{~mm}$, width in the narrow Sect. $4.8 \mathrm{~mm}$, thickness $1.35 \mathrm{~mm}$, length $90 \mathrm{~mm}$ ) used for the tensile tests (Fig. 2) and disintegration tests carried out by Altieri et al. [21] under controlled composting conditions at different temperature $\left(58\right.$ and $\left.25^{\circ} \mathrm{C}\right)$, according to international standards. In the injection press the temperature profile in the three zones was 125,135 and $145^{\circ} \mathrm{C}$, mold temperature of $15-25^{\circ} \mathrm{C}$, injection and post pressure of 20-25 and 20-35 bar, respectively, and cycle time of $30 \mathrm{~s}$.

In addition, the pellets were also used to produce sheets with thickness of 200-300 $\mu \mathrm{m}$ by a lab hot press (model $10 \mathrm{~T}$ press, NOSELAB ATS s.r.l, Nova Milanese (MB), Italy) at $170{ }^{\circ} \mathrm{C}$. The hot-pressed films were used in the disintegration tests under simulated composting conditions reported by Altieri et al. [21].

\section{Characterization}

\section{Thermogravimetric Analysis}

Thermogravimetric analysis (TGA) was performed on the starting materials (PBSA, $\mathrm{HCa}$ and $\mathrm{HCe}$ ) and the PBSA/ HC blends in form of pellets by a TA Q-500 (TA Instruments, Waters LLC, New Castle, DE, USA). About $15 \mathrm{mg}$ of sample were loaded into a platinum pan and heated from room temperature to $800{ }^{\circ} \mathrm{C}$ at $10^{\circ} \mathrm{C} / \mathrm{min}$ under nitrogen atmosphere. TGA was used to evaluate the thermal stability of the different used $\mathrm{HCs}$ in view of their processing by
Table 2 Temperature profiles adopted in the extruder for the different PBSA/HC blends

\begin{tabular}{llllllllllll}
\hline \multicolumn{1}{c}{ Feed } & \multicolumn{10}{c}{ Head } \\
\hline Blends & $\mathrm{T}_{1}\left({ }^{\circ} \mathrm{C}\right)$ & $\mathrm{T}_{2}\left({ }^{\circ} \mathrm{C}\right)$ & $\mathrm{T}_{3}\left({ }^{\circ} \mathrm{C}\right)$ & $\mathrm{T}_{4}\left({ }^{\circ} \mathrm{C}\right)$ & $\mathrm{T}_{5}\left({ }^{\circ} \mathrm{C}\right)$ & $\mathrm{T}_{6}\left({ }^{\circ} \mathrm{C}\right)$ & $\mathrm{T}_{7}\left({ }^{\circ} \mathrm{C}\right)$ & $\mathrm{T}_{8}\left({ }^{\circ} \mathrm{C}\right)$ & $\mathrm{T}_{9}\left({ }^{\circ} \mathrm{C}\right)$ & $\mathrm{T}_{10}\left({ }^{\circ} \mathrm{C}\right)$ & $\mathrm{T}_{11}\left({ }^{\circ} \mathrm{C}\right)$ \\
PHa & 155 & 165 & 165 & 160 & 160 & 160 & 160 & 160 & 160 & 165 & 170 \\
PHe & 155 & 170 & 170 & 170 & 170 & 165 & 165 & 165 & 165 & 170 & 170 \\
\hline
\end{tabular}


Fig. 2 Tensile dog-bone specimens of PBSA and PBSA/HC blends

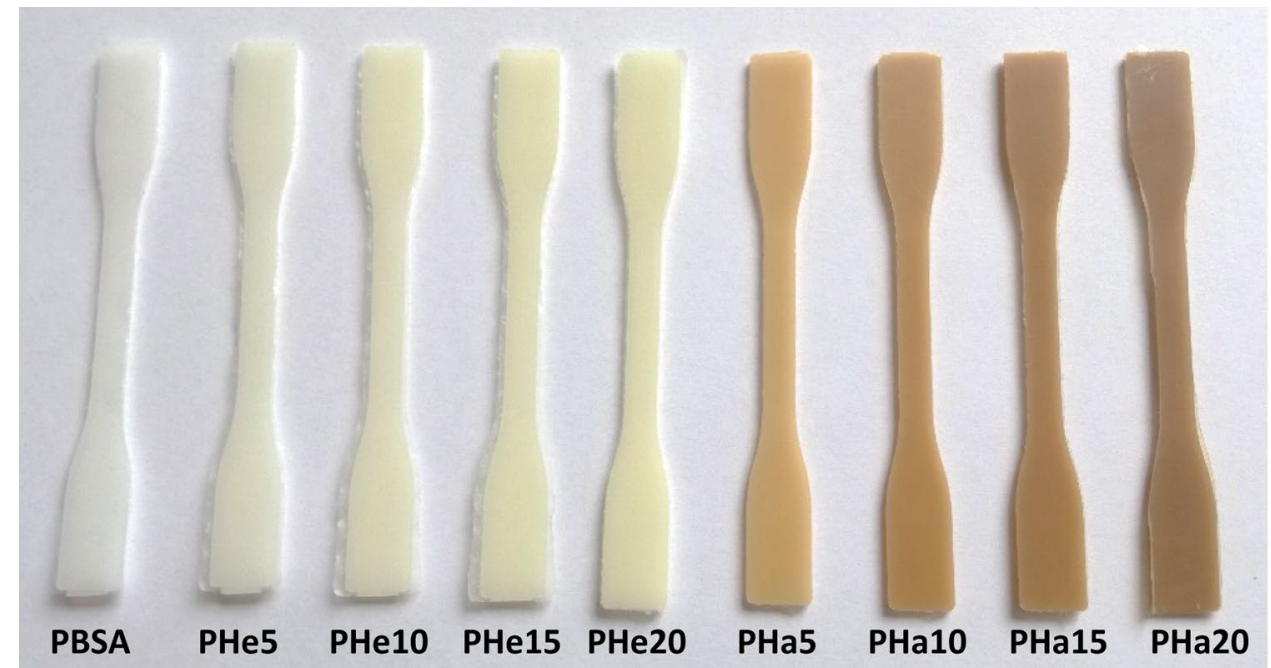

melting extrusion with PBSA and the effect of HCs on the thermal behavior of PBSA.

\section{Differential Scanning Calorimetry}

Differential scanning calorimetry (DSC) was carried out on the HCs and blend pellets by a Perkin Elmer Pyris 1 (Perkin Elmer Instrument, Waltham, MA, U.S.) under nitrogen flow $(50 \mathrm{~mL} / \mathrm{min})$. About $25 \mathrm{mg}$ of pellets were put in a hermetically sealed aluminum pan and subjected to first heating/cooling/second heating at $10 / 20 / 10^{\circ} \mathrm{C} / \mathrm{min}$, respectively, beginning with heating from 20 to $150{ }^{\circ} \mathrm{C}$ (to remove any thermal history from processing), cooling to $0{ }^{\circ} \mathrm{C}$, and subsequently heating to $150{ }^{\circ} \mathrm{C}$. The melting temperature $\left(\mathrm{T}_{\mathrm{m}}\right)$ and enthalpy $\left(\Delta \mathrm{H}_{\mathrm{m}}\right)$ were determined by the second heating DSC data and used to evaluate the crystallinity $\chi_{c}$ of PBSA by the Eq. (1):

$\chi_{c}(\%)=\frac{\Delta H_{m}}{\Delta H_{m}^{0} \cdot f_{w}} 100 \%$

where $\Delta H_{m}^{0}$ is the melting enthalpy per gram of the $100 \%$ crystalline PBSA (142 J/g; [22]), and the $f_{w}$ is the weight fraction of PBSA in the blend.

\section{Fourier Transform Infrared (FTIR) Analysis}

FTIR spectroscopy was used to investigate the primary and secondary structure of the used HCs and the possible intermolecular interactions occurred between the functional groups of HCs and those of PBSA. FTIR spectra were recorded on a Perkin Elmer Spectrum One FT-IR Spectrometer (Perkin Elmer, Waltham, MA, USA), equipped with a Perkin Elmer Universal ATR Sampling Accessory, in the wavenumber range of $4000-650 \mathrm{~cm}^{-1}$ at $4 \mathrm{~cm}^{-1}$ scanning resolution. FTIR spectroscopy was carried on the HCs in form of powder and on the pellets of neat PBSA and PBSA/HC blends. All the samples were pre-dried at $40{ }^{\circ} \mathrm{C}$ in a vacuum oven for $24 \mathrm{~h}$ before the FTIR analysis.

\section{Mechanical Tests}

Tensile properties of injection molded Haake III Type (557-2290) dog-bone specimens of neat PBSA and PBSA/ HC blends were evaluated in accordance with ASTM D 638 using an Instron 5500R tensiometer (Instron, Norwood, MA, USA), equipped with a $1 \mathrm{kN}$ load cell. The tensile tests were carried out at room temperature with a crosshead speed of $10 \mathrm{~mm} / \mathrm{min}$. For each sample, at least 5 replicates were carried out.

\section{Rheological Properties}

In order to evaluate the effect of the different used HCs on the fluidity of the melt PBSA/HC blends, the Melt Flow Rate (MFR) and Melt Volume Rate (MVR) measurements were carried out according to UNI EN ISO 1133 by a Ceast Melt Flow Tester MF20 (Instron, Canton, MA, USA) equipped with automatic weight lifting and cutting systems. MFR and MVR represent the amount of melt polymer, expressed in mass (grams) and volume $\left(\mathrm{cm}^{3}\right)$, respectively, flowing per 10 min through a capillary of specific diameter and length under a pressure applied at a specified temperature. $4.5 \mathrm{~g}$ of sample pellets were heated at $150{ }^{\circ} \mathrm{C}$ in the barrel and extruded through the normalized die (diameter $2.095 \mathrm{~mm}$ ) under a constant load of $2.16 \mathrm{~kg}$. MFR and MVR of PBSA and PBSA/HC blends were measured and the melt density was evaluated by the ratio MFR/MVR. 
In addition, the melt rheological measurements were carried out by an MCR 92 Rheometer (Anton Paar Italia, Rivoli, Italy) using a plate-plate geometry ( $25 \mathrm{~mm}$ diameter, $2 \mathrm{~mm}$ gap) in the temperature range of $130-160{ }^{\circ} \mathrm{C}$. Sample in form of pellets was used for each run and a waiting time of 3 min was applied for each test. All the samples were dried before testing and for each sample, 3 replicates were carried out.

\section{Scanning Electron Microscopy}

Neat PBSA and PBSA/HC pellets were fractured in liquid nitrogen and the fracture surfaces were observed by scanning electron microscopy (SEM) using a Quanta FEG 450 (FEI Inc.) coupled to an energy dispersive X-ray spectrometer (EDS). EDS microanalysis was also conducted to obtain information on the dispersion of the different $\mathrm{HC}$ in the PBSA matrix, since $\mathrm{HCs}$ contain salts such as $\mathrm{NaCl}$ (Table 1). Before the SEM analysis, the fractured sections were coated with a homogeneous layer (5-6 nm thickness) of Au by a SEM coating device (Edward Spotter Coater) to induce electroconductivity.

\section{Results and Discussion}

\section{Processing}

The PBSA/HC blends containing up to $20 \mathrm{wt} \% \mathrm{HCs}$ did not show any problem during the extrusion process showing that the addition of HCs to the PBSA did not compromise its processability. While, during the injection molding, the extrusion and mold temperatures were slightly reduced with the increasing the $\mathrm{HC}$ content to compensate the increase of blend fluidity for $\mathrm{HCa}$ and to reduce the possible development of volatile compounds that lead to molding volume contraction with consequent formation of localized sink marks on the specimen surface. Figure 2 shows some of the dog-bone specimens produced from neat PBSA and PBSA/ $\mathrm{HC}$ blends. As shown, the dog-bones containing HCe appear slightly yellow, while those containing $\mathrm{HCa}$ caramel; the color becomes more intense with increasing the $\mathrm{HC}$ content.

\section{Thermal Properties}

Thermogravimetric (TG) curves as a function of temperature of HCs, PBSA and PBSA/HC blends are shown in Fig. 3. $\mathrm{HCs}$, after initial residual moisture loss, particularly evidenced in $\mathrm{HCa}$, due to its higher hydrophilicity than $\mathrm{HCe}$, presented a further weight loss in the range $150-200{ }^{\circ} \mathrm{C}$ related to the loss of low molecular oligopeptides, and then
Fig. 3 TG curves of HCs, PBSA and PBSA/HC blends under inert atmosphere
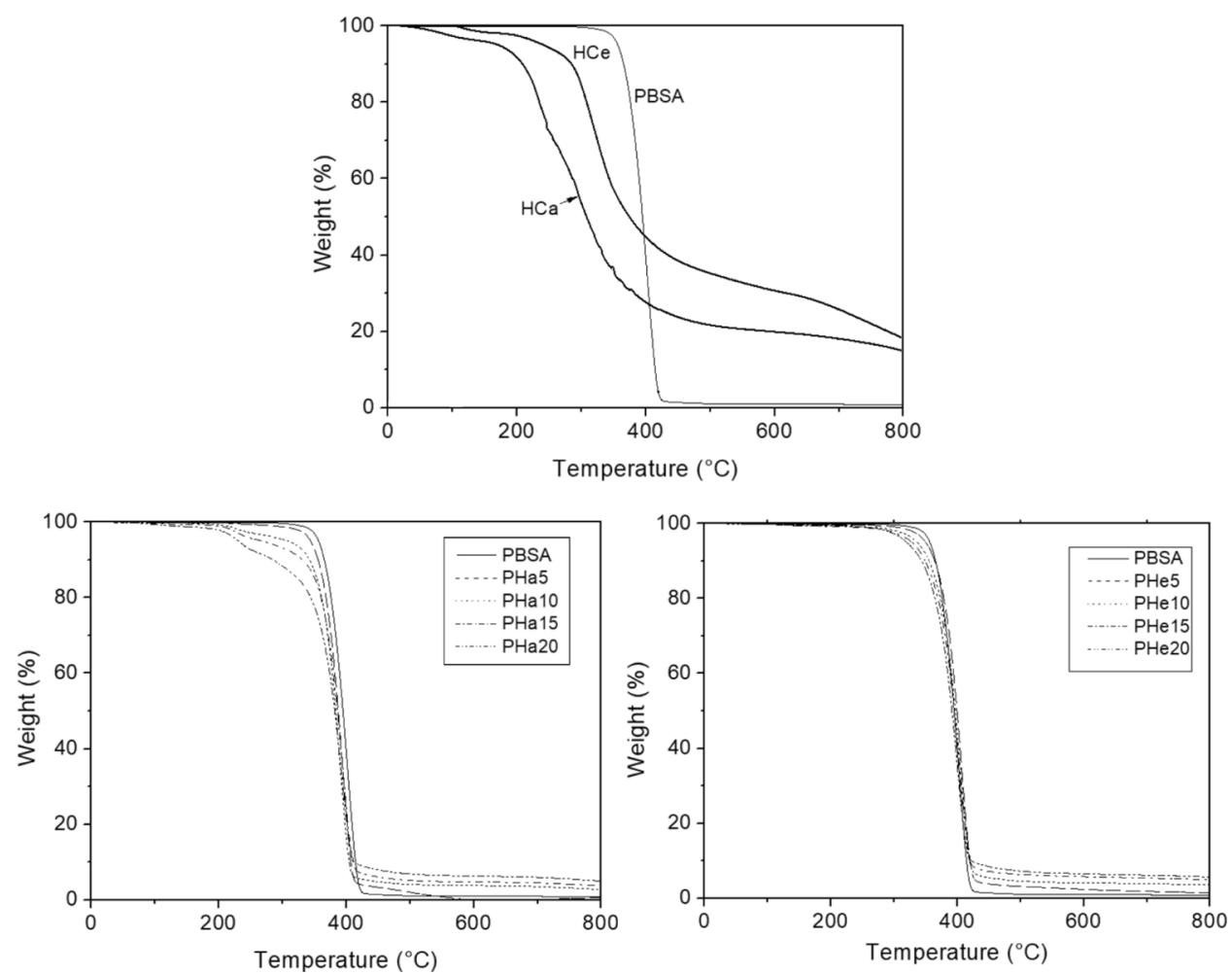
a major weight loss in the range $200-400{ }^{\circ} \mathrm{C}$. The amplitude of this decomposition temperature range is attributable to the distribution of the lengths of the peptide chains and free amino acids. HCe resulted thermally more stable than $\mathrm{HCa}$ showing the thermal degradation curve shifted to higher temperatures (Fig. 3). Furthermore, HCa presented a higher residual weight a $800{ }^{\circ} \mathrm{C}$ than $\mathrm{HCe}$ as expected because of higher content of salts in $\mathrm{HCa}$ (Table 1). The TG curve of PBSA showed thermal stability up to $300{ }^{\circ} \mathrm{C}$ and, then, a single-stage thermal degradation with peak close to $400{ }^{\circ} \mathrm{C}$. A negligible residue $(0.3 \%)$ was observed at $800{ }^{\circ} \mathrm{C}$.

The TG curves of the blends derived from the combined effect of the two components, the weight loss in the range 200-250 ${ }^{\circ} \mathrm{C}$, more evident in PHa blends, is attributable to the thermal degradation of the $\mathrm{HC}$ in the blend and the subsequent weight loss to the concomitant thermal degradations of HC and PBSA showing that no significant variation of the thermal stability of PBSA was observed when $\mathrm{HC}$ was incorporated to the polymeric matrix. Thus, the thermal stability of both $\mathrm{HCs}$ up to $150-160^{\circ} \mathrm{C}$ attests their suitability to be processed with thermoplastic polymers having extrusion temperatures below these values such as PBSA without incurring thermal degradation. In addition, given the high hydrophilicity of $\mathrm{HCs}$, in particular $\mathrm{HCa}$, it is necessary to dry them before being processed with PBSA to avoid the development of water vapor during extrusion phase. Differential scanning calorimetry (DSC) was used to investigate the effect of the two HCs on the crystallization behavior of PBSA. The 1st heating scan was omitted and the analyses were focused on the second heating to eliminate any possible interference of the previous thermal history. The DSC curves obtained during the 2nd heating of the HCs, PBSA and the PBSA/HC blends containing $20 \mathrm{wt} \%$ of $\mathrm{HC}$ are reported in Fig. 4.

The melting temperature/s $\left(\mathrm{T}_{\mathrm{m}}\right)$, the melting heat $\left(\Delta \mathrm{H}_{\mathrm{m}}\right)$ normalized to PBSA content, and the PBSA crystallinity index are summarized in the Table 3.

As shown, the neat PBSA and the blend PHa20 show a single endothermic peak at 88 and $87{ }^{\circ} \mathrm{C}$, respectively; while PBSA shows two melting peaks in the blend $\mathrm{PHe} 20$ : the first peak at $75{ }^{\circ} \mathrm{C}$ and the second one at $87^{\circ} \mathrm{C}$. This shows that the presence of $\mathrm{HCe}$ leads to the formation of two crystalline phases of PBSA, one that melts at a temperature lower than that of neat PBSA and the other at the same temperature of the neat PBSA. The total fusion heat $\left(\Delta \mathrm{H}_{\mathrm{m}}\right)$, evaluated by integration of the area under the two melting peaks of PBSA and normalized to PBSA content, decreased slightly in the $\mathrm{PHe} 20$ blend as the crystallinity index; while in the PHa20 blend a marked reduction of $\Delta \mathrm{H}_{\mathrm{m}}$ was observed leading to a reduction of the degree of crystallinity of PBSA from 31 to $19 \%$, as shown in Table 3. Consequently, on the basis of these results, $\mathrm{HCe}$ appeared to hinder the crystallization of PBSA while HCa had a negligible effect.
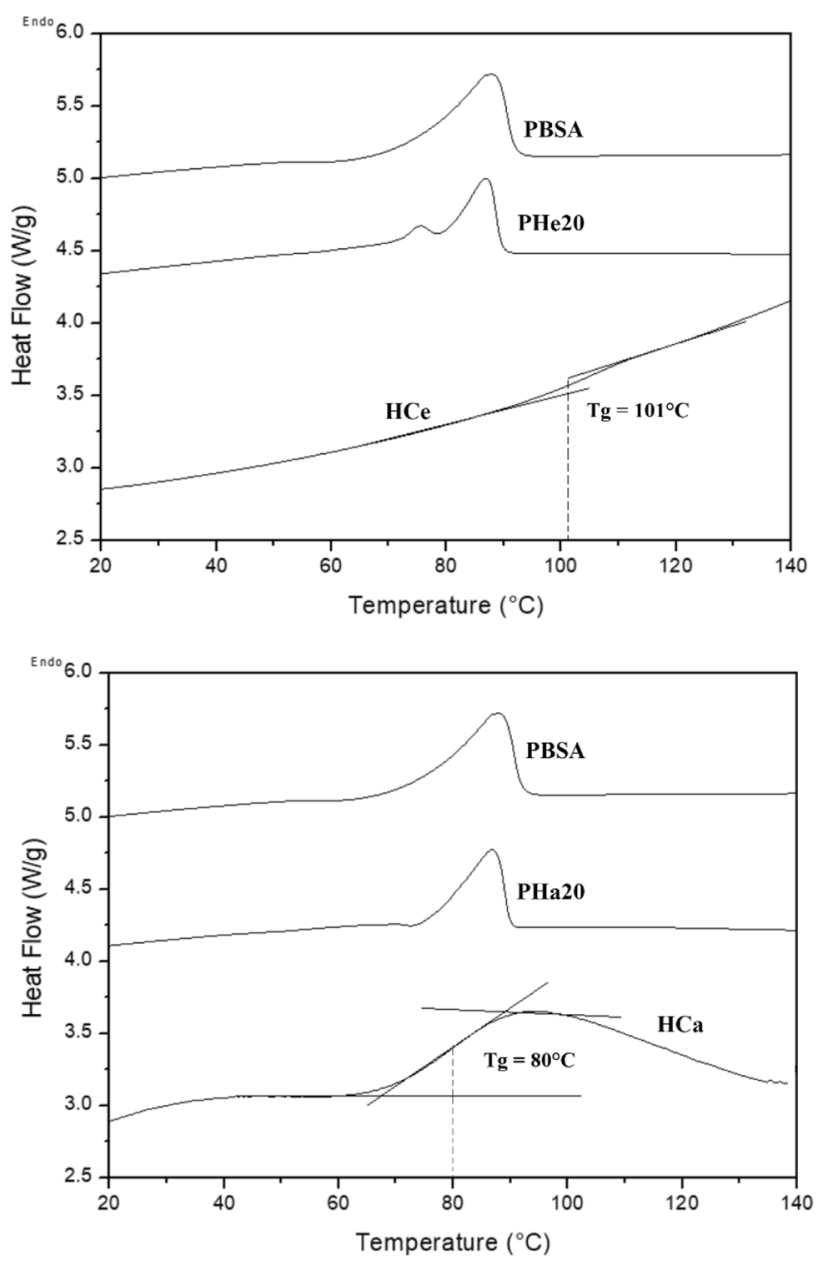

Fig. 4 DSC curves of PBSA, HCs and the PBSA/HC blends with 20 wt $\%$ HC during the 2 nd heating

Table 3 Thermal parameters and crystallinity index of PBSA and its blends with $20 \mathrm{wt} \% \mathrm{HC}$

\begin{tabular}{lllll}
\hline Sample & $T_{m l}\left({ }^{\circ} \mathrm{C}\right)$ & $T_{m 2}\left({ }^{\circ} \mathrm{C}\right)$ & $\Delta H_{m}(\mathrm{~J} / \mathrm{g})$ & $\chi_{\mathrm{c}}$ \\
\hline PBSA & - & 88.0 & 36.6 & 31.3 \\
PHe20 & 75.4 & 87.0 & 22.5 & 19.2 \\
PHa20 & - & 86.8 & 33.0 & 28.2 \\
\hline
\end{tabular}

\section{FTIR Analysis}

The FTIR spectra of neat PBSA, HCs, PHa20 and PHa20 blends and the second derivative spectra of the HCs are reported in Figs. 5 and 6, respectively.

As shown, the spectra of HCs show the typical peaks of amide A, B, I, II and III (about 3300, 3070, 1650, 1550 and $1300 \mathrm{~cm}^{-1}$, respectively [23]). FTIR spectra peaks of PBSA located at 1714 and $1153 \mathrm{~cm}^{-1}$ are assigned to $\mathrm{C}=\mathrm{O}$ and $\mathrm{C}-\mathrm{O}$, respectively. No relevant reaction seemed to take 

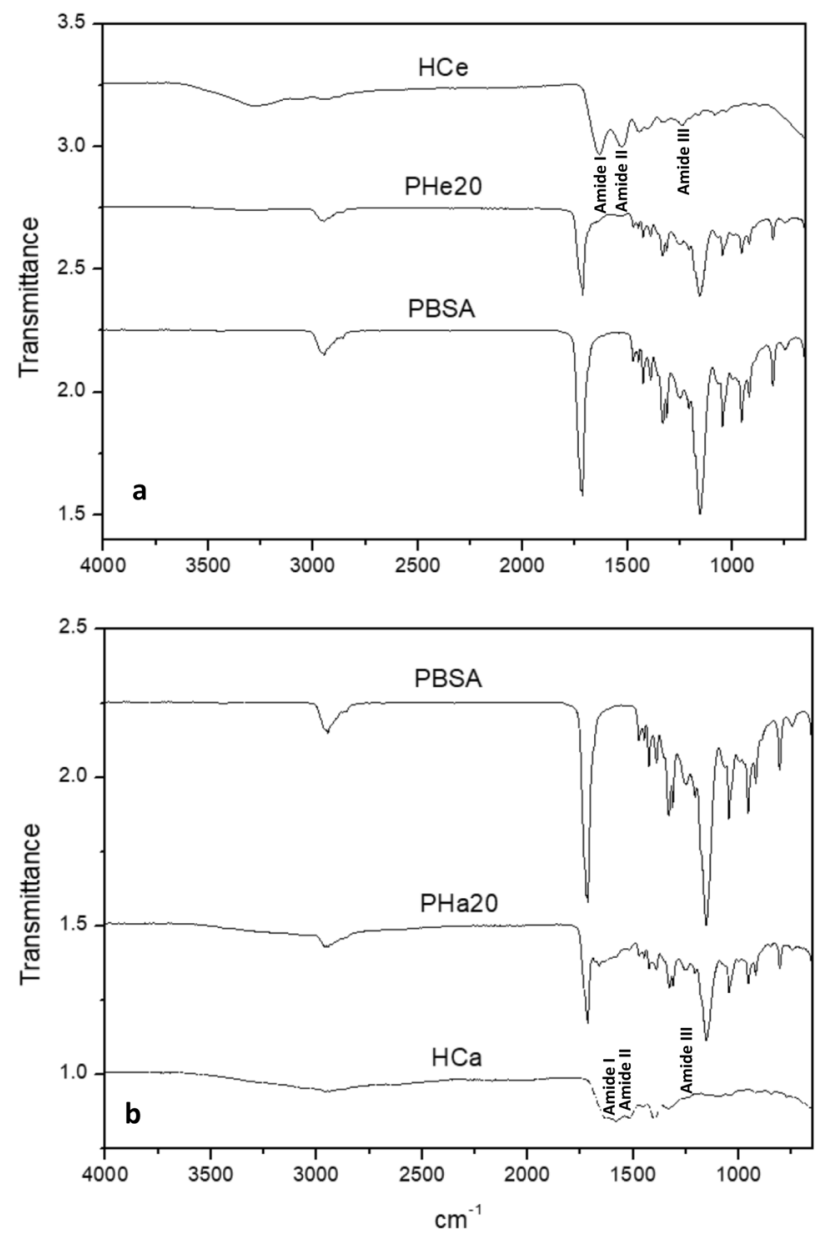

Fig. 5 FTIR spectrum of a neat PBSA, HCe and PHe20; and b neat PBSA, $\mathrm{HCa}$ and $\mathrm{PHa} 20$

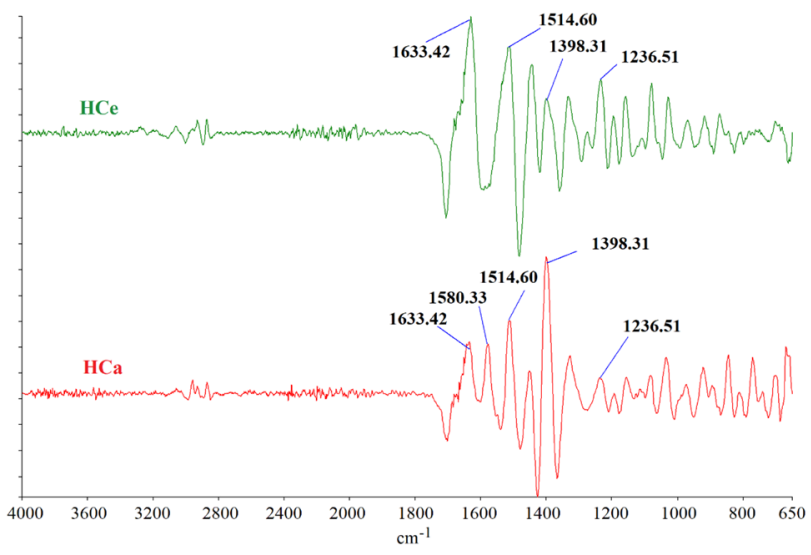

Fig. 6 Second derivative FTIR spectra of the used HCs

place between the PBSA and the collagen hydrolysates: the blend spectrum resulted an overlapping of the typical peaks of the pure components.
The second derivative of FTIR spectra (Fig. 6) shows the differences between the secondary structures of the two used $\mathrm{HC}$. The second derivative spectra clearly resolved peaks that are associated with $\alpha$-helix, $\beta$-strands and turns.

In this case, in both HCs the absence of the peak near to $1650 \mathrm{~cm}^{-1}$ indicates no $\alpha$-helix structures [23]. While, the peak at $1633.42 \mathrm{~cm}^{-1}$ is attributable to $\beta$-sheet conformations [23], and the more intense peak in HCe indicates a higher proportion of $\beta$-sheet structures compared to $\mathrm{HCa}$. In addition, the peak observed in $\mathrm{HCa}$ at $1580 \mathrm{~cm}^{-1}$ is attributable to carboxylates (carboxylic acid salts) due to the presence of oligopeptides or free amino-acids.

In conclusion, as expected, the alkaline hydrolysis resulted more destructive than enzymatic hydrolysis, carried out using exo-endo proteases. For this reason, in the $\mathrm{HCa}$ there is a significant proportion of oligopeptides and free amino acids together with $\beta$-sheet structures. This is confirmed also by the analysis reported in Table 1.

\section{Rheological Properties}

Melt fluidity measurements of the PBSA neat and PBSA/ $\mathrm{HC}$ blends are reported in Fig. 7 in terms of MFR and MVR values obtained at $150{ }^{\circ} \mathrm{C}$. As shown, addition of $\mathrm{HCa}$ decreased significantly the melt viscosity at low shear rate, the MFR and MVR values increased almost linearly with increasing $\mathrm{HC}$ content. This marked decrease of viscosity can be attributed to the alignment of the small chains of $\mathrm{HCa}$ in neighboring macromolecules of PBSA that improves the chain movement with consequent reduction of the melt viscosity. Consequently, $\mathrm{HCa}$ appeared to act as plasticizer due to its good lubrication characteristics which promoted the interphase slip. For content below $15 \mathrm{wt} \%$, as evidenced

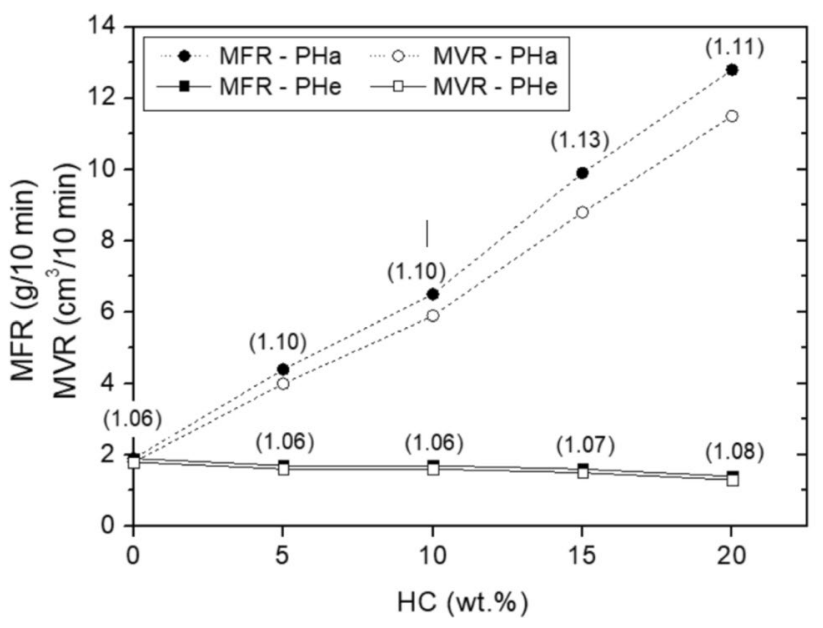

Fig. 7 MFR and MVR values obtained at $150{ }^{\circ} \mathrm{C}$ for neat PBSA and $\mathrm{PBSA} / \mathrm{HC}$ blends; the values in brackets represent the melt density in $\mathrm{g} / \mathrm{cm}^{3}$ evaluated by the MFR/MVR ratio 
by the morphological analysis, $\mathrm{HCa}$ resulted homogeneously dispersed into the polymeric matrix, while above $15 \mathrm{wt} \%$ the presence of macrodomains of $\mathrm{HCa}$ were observed. Consequently, the further increase of MFR and MVR values for high $\mathrm{HCa}$ contents can be attributable to the lubricant effect of $\mathrm{HCa}$ along the barrel walls that facilitated the sliding of the molten material.

As shown in Fig. 7, a totally different behavior was observed for the PBSA/HC blends containing HCe. For these blends, the melt fluidity decreased slightly with increasing the HCe content. As observed by morphological analysis, the powder of HCe appeared homogeneously dispersed in the blend but the weaker interfacial interactions between $\mathrm{HCe}$ and PBSA and the lower lubricant capacity of $\mathrm{HCe}$ compared with those of $\mathrm{HCa}$ led to a reduction of polymer chain mobility with increasing the content of HCe particles which perturb the normal flow and hinder the mobility of chain segments in melt flow, consequently decreasing the blend fluidity. This rheological behavior is typical of the filled polymer composites where the melt viscosity increases with increasing filler content [24, 25]. Therefore, HCe resulted to act as filler in the blend as evidenced also by the SEM analysis and by observations with the naked eye carried out on the PBSA/HCe films and dog bone specimens.

As example, Fig. 8 show the complex viscosity vs frequency for the neat PBSA and PBSA/HC blends obtained at 130 and $150{ }^{\circ} \mathrm{C}$. As expected, the complex viscosity decreased with increasing the temperature and decreased with increasing the frequency, showing a non-Newtonian fluid behavior over entire frequency range with a characteristic shear thinning [26-28]. At the investigated temperatures and in the frequency range that coincides with the characteristic frequencies of the extrusion process (1-1000 rad/s, TA Instrument application note [29]), the blends containing $\mathrm{HCa}$ showed lower viscosities compared to the neat PBSA, while the blends with $\mathrm{HCe}$ higher viscosities. This trend confirms the plasticizing effect of $\mathrm{HCa}$ and the filler effect of HCe: the melt viscosity decreased with increasing the $\mathrm{HCa}$ while it increased with increasing the $\mathrm{HCe}$ content.

\section{Morphological Analysis}

As example, Fig. 9 show the SEM images of the cross-sections of the pellets of PBSA and PBSA/HC blends containing 10 and $20 \mathrm{wt} \%$ of $\mathrm{HC}$. In addition, to investigate the dispersion of HCs in the PBSA matrix, SEM-EDS microanalysis was performed given that HCs contain nitrogen and salts (see Table 1 ) as sodium chloride, $\mathrm{NaCl}$ (deriving from the raw hide salting), unlike PBSA. As example, the SEM-EDS analysis performed on the PHe10 and PHa20 pellet is reported in Figs. 10 and 11, respectively. As shown in Fig. 9b, c, the blends PHe10 and PHe20 show two distinct phases: the disperse phase, attributable to the HCe as confirmed by the SEM-EDS analysis (Fig. 10), appears as spheroid particles dispersed in the continuous phase of PBSA. Poor cohesion is shown between the two phases, indicating poor interactions between HCe and PBSA (the HC particles resulted separate from the matrix). In the blends containing $\mathrm{HCa}$ (Fig. 9d, e), HC resulted homogeneously dispersed into the polymeric matrix showing a good compatibility with PBSA. In the PHa10 no evident phase separation is observable; while in the PHa20 micro-domains of $\mathrm{HC}$ are uniformly distributed in the sample. As shown by the SEM-EDS analysis (Fig. 11), it is not possible to identify on a microscopic scale zones consisting only of PBSA or only of $\mathrm{HCa}$. It is to be pointed out that the density of $\mathrm{HC}$ is much lower than that of PBSA $\left(0.55 \mathrm{~g} / \mathrm{cm}^{3}\right.$ (Table 1) vs $1.24 \mathrm{~g} / \mathrm{cm}^{3}$ of PBSA), so the percentage by volume of HC in the blend is much higher than that in mass, about twice (20 wt $\%$ corresponds to about 40 vol.\%). Despite this, no macro domains of $\mathrm{HCa}$ are observed in the continuous phase.

\section{Mechanical Properties}

The tensile properties of the dog-bone specimens are reported in Table 4. As shown, the Young's modulus decreased with increasing $\mathrm{HCa}$ loading showing a softening effect induced by $\mathrm{HCa}$, in particular for high $\mathrm{HC}$ contents. Stress-strain curves of the PBSA/HCa blends were
Fig. 8 Complex viscosity versus frequency of PBSA and PBSA/ $\mathrm{HC}$ blends at 130 and $150^{\circ} \mathrm{C}$
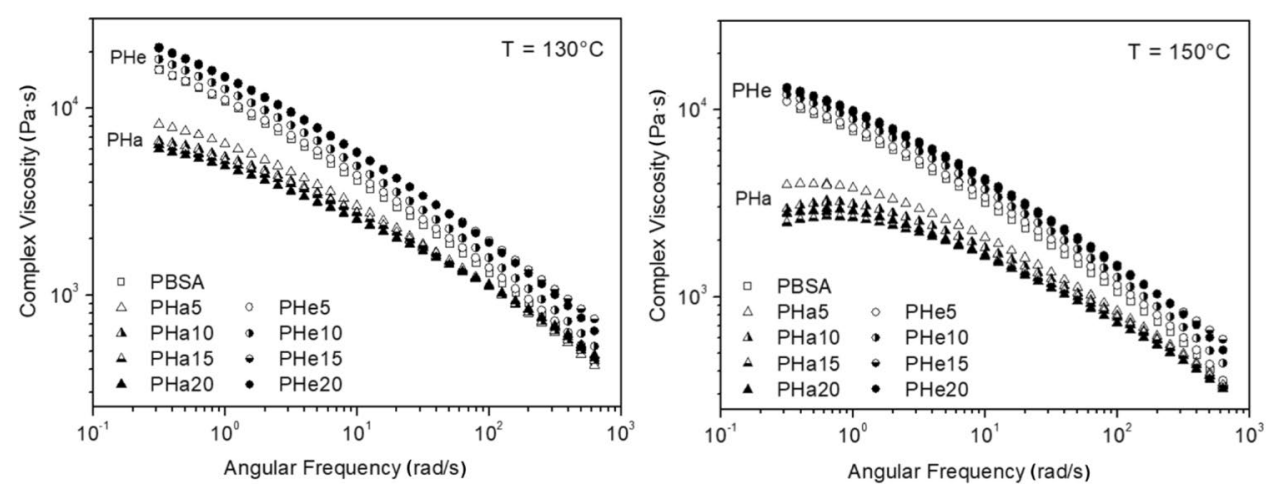
Fig. 9 SEM images of the fractured transversal sections of a neat PBSA (2000X), b PHe10 (500X, 2000X), c PHe20 (500X, 2000X); d PHa10 (2000X) and e PHa20 (2000X) pellets

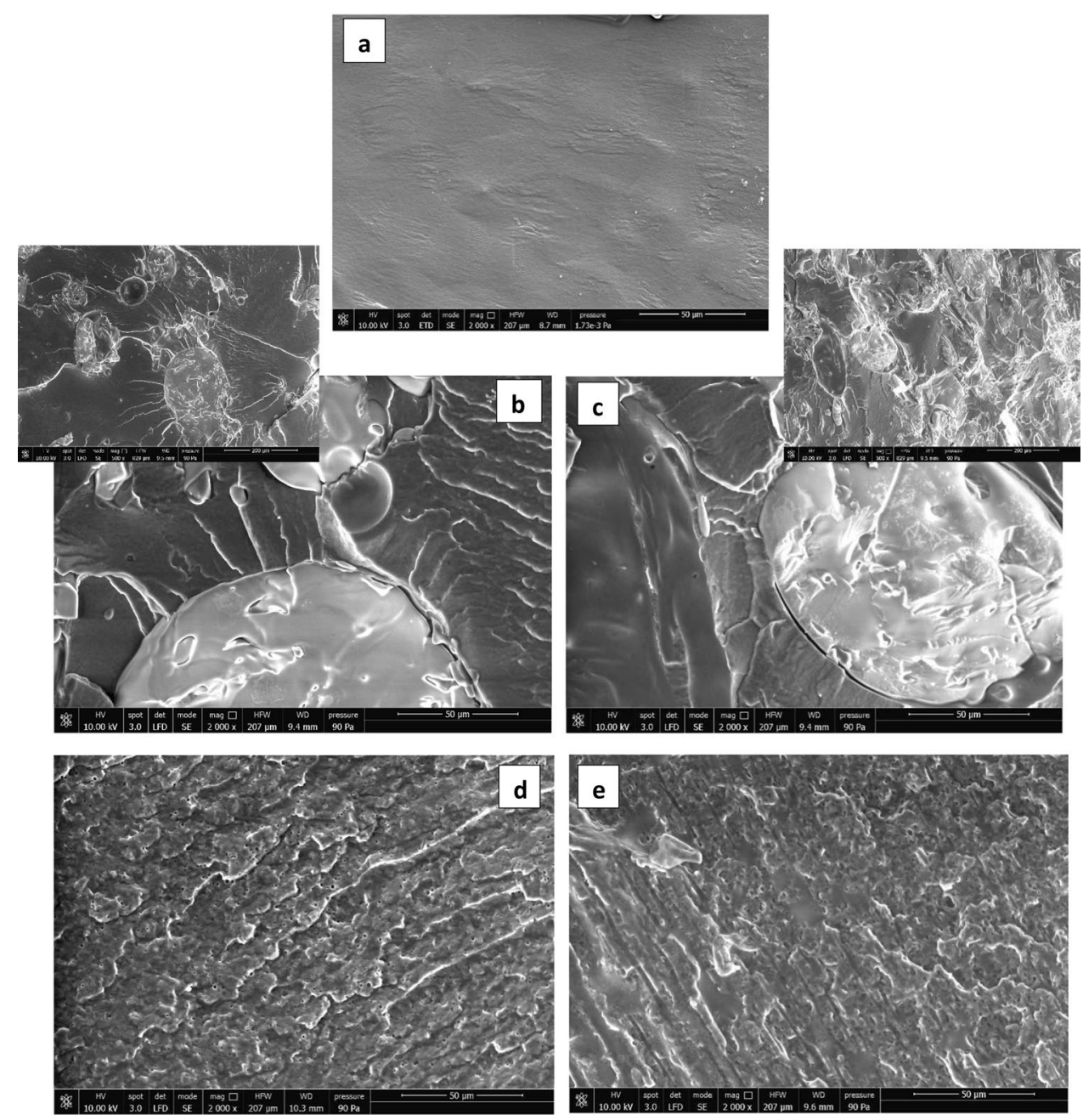

characterized by a yield strength similar to that of neat PBSA but at higher elongation; the stress at break decreased with increasing of $\mathrm{HCa}$ content while the elongation at break resulted higher or similar to that of neat PBSA. For the blends PBSA/HCe, a gradual increase in the Young's modulus was induced by the addition of $\mathrm{HCe}$, showing its stiffening effect. According to the increase of rigidity, the elongation at break showed a marked decrease also at low percentage of $\mathrm{HCe}$ (5 wt.). These results are in accordance with those obtained by Dascălu et al. [18] because of poor adhesion between LDPE and HC. In conclusion, the blends $\mathrm{PBSA} / \mathrm{HC}$ with $\mathrm{HCe}$ produce a more rigid structure compared to the blends with $\mathrm{HCa}$ confirming the plasticizing effect of $\mathrm{HCa}$ and the filler effect of $\mathrm{HCe}$.

\section{Conclusions}

Blends of PBSA and two different raw hydrolyzed collagens from leather shavings were successfully processed by extrusion and injection molding up to a content of $20 \mathrm{wt} \%$ HC. HCs thermal stability was compatible with the melt processing of PBSA. The different secondary structure of the two HCs investigated influenced the rheological behavior of the molten blend and the mechanical performance. The $\mathrm{HC}$ obtained by alkaline hydrolysis ( $\mathrm{HCa}$ ) showed a good compatibility with PBSA, as evidenced by the morphological analysis, and acted as plasticizer with consequent reduction of the melt viscosity making the PBSA/HC blend softer. While the collagen hydrolysate obtained by enzymatic hydrolysis (HCe) showed lower compatibility with the polymeric matrix and behaved as a filler making the blends little more rigid with the increasing of its content in the blend.

The molted dog-bone specimens of both blend series showed good flexibility and satisfactory mechanical 
Fig. 10 SEM-EDS microanalysis performed on the cross-sections of PHe10 pellet
Fig. 11 SEM-EDS microanalysis performed on the cross-sections of PHa20 pellet
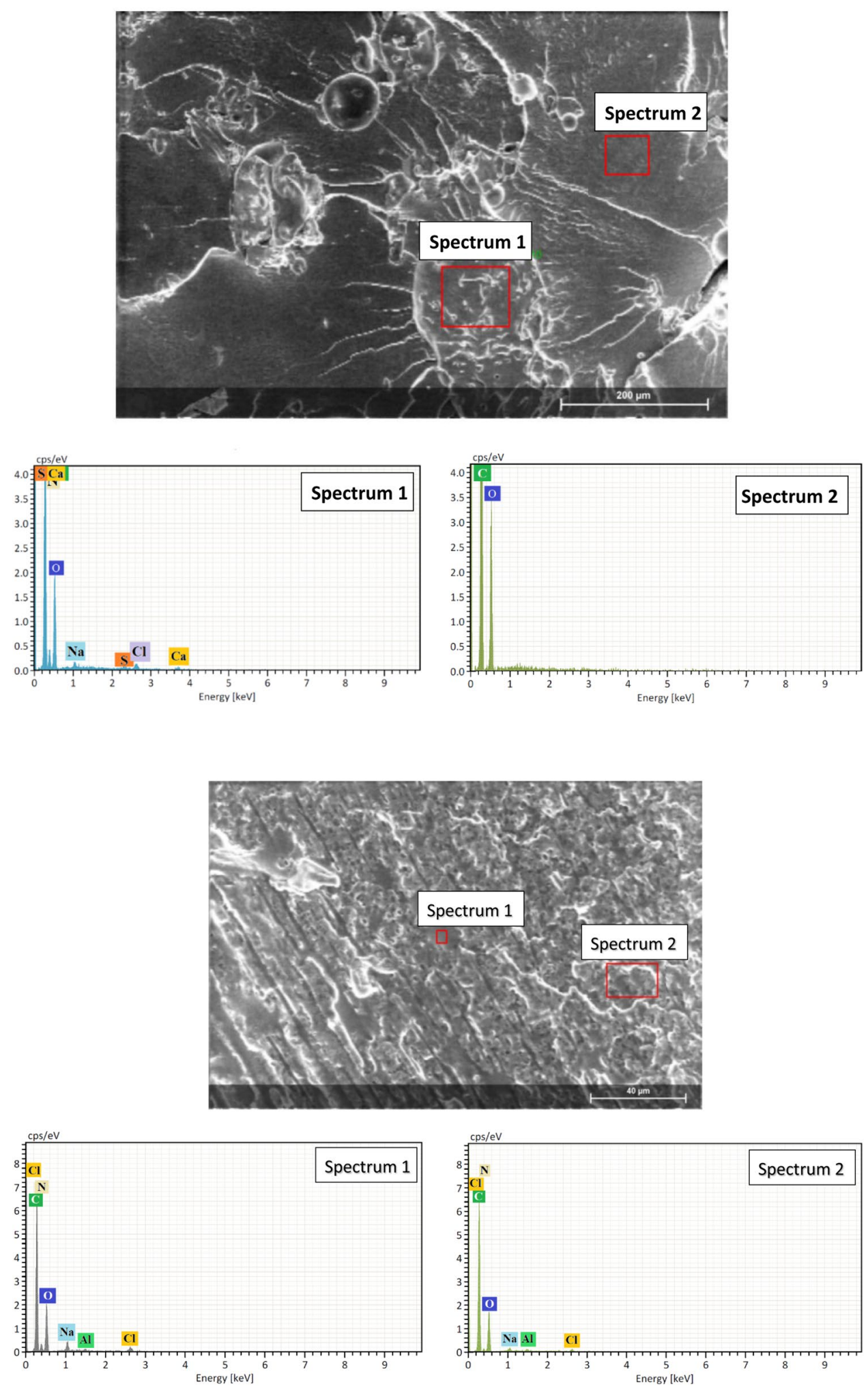

properties in the absence of crosslink agent and/or compatibilizing agents.

In conclusion, PBSA matrix showed a good capability to incorporate the two different investigated HCs without compromising its melt processability up to $20 \mathrm{wt} \%$ of $\mathrm{HC}$ and the developed PBSA/HC blends appear promising candidates for the production of biodegradable/compostable items such as plant molded plots having fertilizing 
Table 4 Mechanical properties of the tensile PBSA and PBSA/HC specimens

\begin{tabular}{llllll}
\hline Sample & \multicolumn{2}{l}{$\begin{array}{l}\text { Young's modulus } \\
(\mathrm{GPa})\end{array}$} & Yield strength $(\mathrm{MPa})$ & $\begin{array}{l}\text { Elongation at yield } \\
(\%)\end{array}$ & $\begin{array}{l}\text { Stress at break }(\mathrm{MPa}) \\
\text { Elongation at break }(\%)\end{array}$ \\
\hline PBSA & $0.32 \pm 0.01$ & $17.5 \pm 1.3$ & $20.1 \pm 1.3$ & $28.4 \pm 2.1$ & $776.0 \pm 24.8$ \\
PHa5 & $0.29 \pm 0.03$ & $14.8 \pm 0.3$ & $24.1 \pm 0.3$ & $23.7 \pm 0.6$ & $715.1 \pm 35.5$ \\
PHa10 & $0.13 \pm 0.06$ & $13.5 \pm 0.2$ & $27.5 \pm 0.2$ & $23.6 \pm 0.4$ & $805.3 \pm 29.1$ \\
PHa15 & $0.12 \pm 0.04$ & $12.8 \pm 1.1$ & $34.1 \pm 1.1$ & $20.1 \pm 1.0$ & $802.5 \pm 46.2$ \\
PHa20 & $0.10 \pm 0.01$ & $12.2 \pm 0.7$ & $28.2 \pm 0.7$ & $11.7 \pm 2.1$ & $809.9 \pm 68.1$ \\
PHe5 & $0.37 \pm 0.08$ & $16.0 \pm 0.3$ & $16.0 \pm 0.3$ & $21.9 \pm 2.1$ & $225.0 \pm 10.2$ \\
PHe10 & $0.39 \pm 0.01$ & $15.2 \pm 0.8$ & $10.1 \pm 0.8$ & $20.1 \pm 1.7$ & $187.5 \pm 12.5$ \\
PHe15 & $0.38 \pm 0.03$ & $12.4 \pm 1.2$ & $13.2 \pm 1.2$ & $18.1 \pm 1.1$ & $131.2 \pm 10.7$ \\
PHe20 & $0.43 \pm 0.08$ & $13.5 \pm 1.3$ & $9.9 \pm 1.3$ & $20.0 \pm 0.9$ & $102.5 \pm 21.1$ \\
\hline
\end{tabular}

Mean values \pm standard deviation of 5 replicates

properties, given the presence of $\mathrm{HC}$, for applications in agriculture and represent an opportunity for valorizing these by-products of the tanning industry in the bioplastic sector.

Acknowledgements The authors would like to thank Eng. Dr. Giancarlo Bernini Carri (Consorzio SGS SpA, Italy) and Dr. Alfonso Iannone (ILSA SpA, Italy) for kindly providing collagen hydrolysates $\mathrm{HCa}$ and $\mathrm{HCe}$, respectively, and the relative analyses; Dr. Niccoletta Barbani for her support in carrying out the DSC and FTIR analysis and her precious technical comments; Mrs. Irene Anguillesi for her support in carrying out the rheological tests; Dr. Randa Ishak for the SEM analysis; Dr. Marco Sandroni for his support in the processing of the blends and in carrying the tensile tests.

Funding Open access funding provided by Università di Pisa within the CRUI-CARE Agreement. This research was funded by University of Pisa (Project PRA_2018_75; Title: Development/production/validation of "active" bioplastics for agricultural applications. Acronym: BIOPLASFER)

Open Access This article is licensed under a Creative Commons Attribution 4.0 International License, which permits use, sharing, adaptation, distribution and reproduction in any medium or format, as long as you give appropriate credit to the original author(s) and the source, provide a link to the Creative Commons licence, and indicate if changes were made. The images or other third party material in this article are included in the article's Creative Commons licence, unless indicated otherwise in a credit line to the material. If material is not included in the article's Creative Commons licence and your intended use is not permitted by statutory regulation or exceeds the permitted use, you will need to obtain permission directly from the copyright holder. To view a copy of this licence, visit http://creativecommons.org/licenses/by/4.0/.

\section{References}

1. Ratto JA, Stenhouse PJ, Auerbach M, Mitchell J, Farrell R (1999) Polymer 40:6777. https://doi.org/10.1016/S0032-3861(99)00014 $-2$

2. Ishioka DR, Kitakuni E, Ichikawa Y (2002) Aliphatic polyesters: bionolle. Bipolymers, polyesters III. Wiley, New York

3. Fujimaki T (1998) Polym Degrad Stab 159:209. https://doi. org/10.1016/S0141-3910(97)00220-6
4. Mitchell M, Ryder T, Hirt D (2017) Degradation of PBSA in water, SPE ANTEC Anaheim. 482.

5. Takiyama E, Fujimaki T, Seki S, Hokari T, Hatano Y (1994) Method for manufacturing biodegradable high molecular aliphatic polyester, US Patent 5,306,787.

6. Nishioka M, Tuzuki T, Wanajyo Y, Oonami H, Horiuchi T (1994) Stud Polym Sci 12:584. https://doi.org/10.1016/B978-0-44481708-2.50069-5

7. Zini E, Scandola M (2011) Polym Compos 2:1905. https://doi. org/10.1002/pc.21224

8. Phua YJ, Pegoretti A, Araujo TM, Ishak ZAM (2015) J Appl Polym Sci 132:42815. https://doi.org/10.1002/app.42815

9. Muthuraj R, Misra M, Mohanty AK (2015) 5-Studies on mechanical, thermal, and morphological characteristics of biocomposites from biodegradable polymer blends and natural fibers, biocomposites-design and mechanical performance. Woodhead Publ Ser Compos Sci Eng. https://doi.org/10.1016/B978-1-78242 $-373-7.00014-7$

10. Kasirajan S, Ngouajio M (2012) Agron Sustain Dev 32:501. https ://doi.org/10.1007/s13593-012-0132-7

11. Steeves DM, Farrell R, Ratto JA (2007) J Biobased Mater Bioenergy 1:94. https://doi.org/10.1166/jbmb.2007.011

12. Wang X-L, Yang K-K, Wang Y-Z (2003) J Macromol Sci Part C 43:385. https://doi.org/10.1081/MC-120023911

13. Seggiani M, Altieri R, Puccini M, Stefanelli E, Esposito A, Castellani F, Stanzione V, Vitolo S (2018) Polym Degrad Stab 150:13. https://doi.org/10.1016/j.polymdegradstab.2018.02.001

14. Vitolo S, Puccini M, Seggiani M, Castiello D (2016) Thermoplastic polymer composition, Patent: WO 2016035021 A1.

15. Chiellini E, Cinelli P, Ilieva VI, Ceccanti A, Alexy P, Bakos D (2003) Macromol Symp 197:125. https://doi.org/10.1002/ masy.200350712

16. Crivoi F, Stefan L, Moldovan L, Vasile C (2009) J Optoelectron Adv Mater 11:356

17. Castiello D, Chiellini E, Cinelli P, D’Antone S, Puccini M, Salvadori M, Seggiani M (2009) J Appl Polym Sci 114:3827. https:// doi.org/10.1002/app.31000

18. Dascălu MC, Vasile C, Silvestre C, Pascu M (2005) Eur Polym J 41:1391. https://doi.org/10.1016/j.eurpolymj.2004.12.005

19. Lungu M, Pascu MC, Bumbu GG, Darie H, Vasile C, Moldovan L (2004) Int J Polym Mater 53:525. https://doi.org/10.1080/00914 030490267636

20. Japan BioPlastics Association. https://www.jbpaweb.net/engli sh/e-gp-products.htm. Accessed 16 May 2020

21. Altieri R, Seggiani M, Cinelli P, Esposito A, Stanzione V (2020) Thermoplastic blends based on poly(butylene 
succinate-co-adipate) and different collagen hydrolysates from tanning industry-II: aerobic biodegradation and compostability. J Polym Environ.

22. Pradeep SA, Kharbas H, Turng L-S, Avalos A, Lawrence JG, Pilla S (2017) Polymers 9(1):22. https://doi.org/10.3390/polym90100 22

23. Barth A (2007) Biochem Biophys Acta 1767:1073. https://doi. org/10.1016/j.bbabio.2007.06.004

24. Móczó J, Pukánszky B (2017) Particulate fillers in thermoplastics. In: Rothon R (ed) Fillers for polymer applications. Polymers and polymeric composites: a reference series. Springer, Cham

25. Hornsby P (2017) Compounding of particulate-filled thermoplastics. In: Rothon R (ed) Fillers for polymer applications. Polymers and polymeric composites: a reference series. Springer, Cham

26. Li H, Huneault MA (2007) Polymer (Guildf) 48:6855. https://doi. org/10.1016/j.polymer.2007.09.020
27. Gui Z, Wang H, Gao Y, Lu C, Cheng S (2012) Iran Polym J 21:81. https://doi.org/10.1007/s13726-011-0009-7

28. Chen R, Zou W, Zhang H, Zhang G, Yang Z, Jin G, Qu J (2015) Polym Test 42:60. https://doi.org/10.1016/j.polymertes ting.2015.01.015

29. Franck A (2004) Understanding rheology of thermoplastic polymers. TA Instruments. p. 1-8.

Publisher's Note Springer Nature remains neutral with regard to jurisdictional claims in published maps and institutional affiliations. 